\title{
Stage-Specific Functions of the Small Rho GTPases Cdc42 and Racl for Adult Hippocampal Neurogenesis
}

\author{
Krishna C. Vadodaria, ${ }^{1,2}$ Cord Brakebusch, ${ }^{3}$ Ueli Suter, ${ }^{2}$ and Sebastian Jessberger ${ }^{1,2}$ \\ ${ }^{1}$ Brain Research Institute, Faculty of Medicine, University of Zurich, CH-8057 Zurich, Switzerland, ${ }^{2}$ Institute of Molecular Health Sciences, Department of \\ Biology, Swiss Federal Institute of Technology Zurich, CH-8093 Zurich, Switzerland, and ${ }^{3}$ Molecular Pathology Section, Department of Biomedical Sciences, \\ Biotech Research and Innovation Center, Copenhagen Biocenter, DK-2200 Copenhagen, Denmark
}

The molecular mechanisms underlying the generation, maturation, and integration of new granule cells generated throughout life in the mammalian hippocampus remain poorly understood. Small Rho GTPases, such as Cdc42 and Rac1, have been implicated previously in neural stem/progenitor cell (NSPC) proliferation and neuronal maturation during embryonic development. Here we used conditional genetic deletion and virus-based loss-of-function approaches to identify temporally distinct functions for Cdc42 and Racl in adult hippocampal neurogenesis. We found that Cdc42 is involved in mouse NSPC proliferation, initial dendritic development, and dendritic spine maturation. In contrast, Racl is dispensable for early steps of neuronal development but is important for late steps of dendritic growth and spine maturation. These results establish cell-autonomous and stage-specific functions for the small Rho GTPases Cdc42 and Racl in the course of adult hippocampal neurogenesis.

\section{Introduction}

New granule cells are generated throughout life in the mammalian hippocampus. The levels of hippocampal neurogenesis in the adult brain have been associated with several neuropsychiatric diseases, among them affective disorders and cognitive aging (Zhao et al., 2008). Neural stem/progenitor cells (NSPCs) reside in the subgranular zone of the dentate gyrus (DG) and give rise to neuronally committed progenitors, generating immature neurons that later mature and integrate into the preexisting DG circuitry. Despite the identification of several intrinsic and extrinsic factors that regulate distinct steps in the course of adult neurogenesis, the cellular and molecular mechanisms guiding a dividing NSPC to a fully integrated and mature neuron remain poorly understood (Ming and Song, 2011).

Cdc42 and Racl are part of the family of small Rho GTPases that hydrolyze GTP to GDP. Both Cdc42 and Racl are expressed in a wide variety of tissues and act as binary molecular switches transducing upstream signals to downstream effectors by alternating between the "on" GTP-bound and the "off" GDP-bound state (Schmitz et al., 2000). Using primarily in vitro models, studies have shown that $\mathrm{Cdc} 42$ and Rac1 play central roles in a variety of cellular functions, such as growth, survival, mechanosensa-

\footnotetext{
Received May 2, 2012; revised Nov. 12, 2012; accepted Nov. 13, 2012.

Author contributions: S.J. designed research; K.C.V. performed research; C.B. and U.S. contributed unpublished reagents/analytic tools; K.C.V. analyzed data; K.C.V. and S.J. wrote the paper.

This study was supported by the National Centres for Competence in Research Neural Plasticity and Repair, Swiss National Science Foundation (S.J., U.S.), Zurich Neuroscience Center, Novartis Foundation, Theodore Ott Foundation, and the EMBO Young Investigator program (S.J.). We thank Reto Baumann for experimental help, the ETH Zurich Light Microscopy Screening Center for help with imaging, and Chitranjan Vadodaria for helping to automate data processing.

Correspondence should be addressed to Sebastian Jessberger, Brain Research Institute, University of Zurich, Winterthurerstrasse 190, CH-8057 Zurich, Switzerland. E-mail: jessberger@hifo.uzh.ch.

DOI:10.1523/JNEUROSCI.2103-12.2013

Copyright $\odot 2013$ the authors $\quad 0270-6474 / 13 / 331179-11 \$ 15.00 / 0$
}

tion, adhesion, proliferation, and cell migration (Jaffe and Hall, 2005). In addition, recent studies analyzed the role of Racl and Cdc42 in the developing brain and identified Cdc42 and Rac1 to be involved in the polarity, proliferation, and subsequent migration of neural precursors during embryonic development (Cappello et al., 2006; Fuchs et al., 2009; Leone et al., 2010).

Although adult neurogenesis partially recapitulates embryonic neurogenesis, processes such as activity-dependent maturation, epigenetic regulation, and intrinsic signaling pathways, among others, SOX2, Cdk5, E2F1, Cdk4, and CyclinD1, are known to have distinct functions in these two stages, making it vital to explore signaling pathways in each context (CooperKuhn et al., 2002; Esposito et al., 2005; Schmetsdorf et al., 2005; Jessberger et al., 2009; Jawerka et al., 2010; Artegiani et al., 2011; Hodge and Hevner, 2011). So far, the role of Cdc42 and Racl in the context of adult neurogenesis remains to be elucidated.

In our study, we used conditional deletion of Cdc42 and Rac1 in adult NSPCs and/or their progeny in vitro and in vivo to identify distinct cell-autonomous roles for Cdc42 and Rac1 in adult hippocampal neurogenesis. We show that Cdc42 activity is associated with proliferation, early dendritic growth, and spine maturation of adult hippocampal NSPCs. In contrast, Rac1 knockdown appears to be involved specifically for EGFassociated proliferation in vitro and is crucial in late stages of dendritic growth, arborization, and spine maturation in vivo. Collectively, our data provide novel evidence that Cdc42 and Racl have cell-autonomous and stage-specific roles in adult hippocampal neurogenesis.

\section{Materials and Methods}

Plasmids and viruses. For Rac1 and Cdc42 activity manipulations, fulllength Rac1 and Cdc42 with specific point mutations (T17N) and $5^{\prime}$ vesicular stomatitis virus (VSV) tags were used (Koivisto et al., 2004). Tagged dominant-negative (DN)-Rac1 and DN-Cdc42-containing con- 
structs were gifts from Dr. Kenneth Yamada (National Institutes of Health/National Institute of Dental and Craniofacial Research, Bethesda, $\mathrm{MD})$. DN-Racl and DN-Cdc42 were subcloned into a retroviral backbone containing a chicken- $\beta$-actin (CAG) promoter, followed by an internal ribosomal entry site (IRES) and green fluorescent protein (GFP), as described previously (Jessberger et al., 2008). Control (Con) constructs were the same viral backbone but without the inserts. For retrovirus-based genetic deletion of Racl and Cdc42 in floxed mice a retroviral construct containing a CAG promoter followed by fusion GFP-Cre recombinase or IRES-red fluorescent protein (RFP) was used (Tashiro et al., 2006). Protein overexpression was confirmed by transfection of human embryonic kidney 293T (HEK293T) cells, protein collection after $2 \mathrm{~d}$, and Western blotting (described below). Retroviruses were produced as described previously (Zhao et al., 2006). Viral titers ranged from 1 and $5 \times 10^{7}$ colony forming units $/ \mathrm{ml}$.

Cell culture. For in vitro experiments, we used NSPCs isolated from the DG of 6- to 8-week-old, female Fisher-344 rats or the hippocampus of 6- to 8-week-old Cdc $42^{\mathrm{fl} / \mathrm{fl}}$ and Rac1 ${ }^{\mathrm{fl} / \mathrm{fl}}$ mice (described below), respectively. Cells were grown and maintained according to previously described protocols (Ray and Gage, 2006). All NSPCs were cultured in serum-free media, DMEM-F-12 (glutamax) containing N2 supplement (Invitrogen), and antibiotics (penicillin-streptomycin-fungizon; Invitrogen). In the proliferation condition, rat NSPCs were kept with FGF-2 (20 ng/ml; PeproTech), and mouse NSPCs were grown with FGF-2 plus EGF (both $20 \mathrm{ng} / \mathrm{ml}$; PeproTech). For neuronal differentiation experiments, rat NSPCs were transferred into medium containing retinoic acid and forskolin (RA/FSK) ( 1 and $5 \mu \mathrm{M}$, respectively; Sigma) for the indicated number of days. For neural differentiation of mouse NSPCs, growth factors were sequentially withdrawn, and cells were fixed $10 \mathrm{~d}$ later.

In experiments in which rat DG NSPCs were electroporated with viral constructs expressing GFP or DN-Cdc42/Rac1 constructs, electroporation was performed using a kit according to the instructions of the manufacturer (Amaxa).

For genetic deletion of Racl and Cdc42 in vitro, NSPCs were isolated from hippocampi of adult mice carrying floxed Rac1 or Cdc42 alleles, using the gentleMACS Dissociator (Miltenyi Biotec) and the MACS Neural Tissue Papain Dissociation Kit (Miltenyi Biotec), according to the protocol of the manufacturer. Cells were expanded as neurospheres in DMEM-F-12 (glutamax) media containing B27 supplement (Invitrogen). Cells were then cultured as monolayers in adherent conditions by the addition of heparin (Sigma). Cells were maintained under proliferating conditions and then infected with GFP-Cre-expressing retrovirus, cells were lysed, and protein was collected at the indicated time points (3, 7 , and $10 \mathrm{~d}$ ) for confirmation of protein knockdown (see Fig. $2 A$ ) by Western blotting. NSPCs derived from mice carrying floxed Racl or Cdc42 alleles were transduced with Cre and Con (RFP) viruses. Proliferation was analyzed $5 \mathrm{~d}$ after viral transduction, and neural differentiation was initiated $2 \mathrm{~d}$ after viral transduction. For measuring proliferation in vitro, $10 \mu \mathrm{M}$ 5'-bromo-2'-deoxyuridine (BrdU; Sigma) was used to pulse cells $1 \mathrm{~h}$ before fixation. All NSPCs were grown on poly-ornithine (Invitrogen) and laminin (Invitrogen)-coated plastic plates or etched glass coverslips (for immunocytochemistry).

DN-Cdc42 and DN-Racl (with 5' -VSV tags) overexpression was confirmed by retroviral transfection of HEK293T cells, protein collection $48 \mathrm{~h}$ later, and Western blotting.

Animals and stereotactic injections. All animal experiments were approved by the veterinary office of the Canton of Zurich, Switzerland. For $\mathrm{DN}-\mathrm{Cdc} 42$ and DN-Rac1 retrovirus experiments, 6- to 8-week-old female C57BL/6 mice were used (Janvier). For GFP-Cre retrovirus-based knockdown, $\mathrm{Cdc} 42^{\mathrm{fl} / \mathrm{fl}}$ and $\mathrm{Racl}^{\mathrm{fl} / \mathrm{fl}}$ 6- to 9-week-old female mice were used (Chrostek et al., 2006; Wu et al., 2006). Mice were stereotactically injected with $1.5 \mu \mathrm{l}$ of retroviral suspension into the DG as described previously (Karalay et al., 2011). Coordinates from bregma were $-2 \mathrm{~mm}$ anteroposterior, $\pm 1.5 \mathrm{~mm}$ mediolateral, and $-2.3 \mathrm{~mm}$ dorsoventral from the skull. Animals were killed at 15 or $30 \mathrm{~d}$ postinjection (dpi). Adult female C57BL/6 mice were used to test of potential side effects of prolonged viral Cre expression; animals were killed 30 dpi of a Cre expression retrovirus. To study expression of Cdc42 and Rac1 in NSPC subtypes in vivo, we used transgenic Nestin reporter mice, expressing GFP under the Nestin promoter (NestinGFP) (Yamaguchi et al., 2000). To generate transgenic conditional knock-out mice (Racl-cKO and Cdc42-cKO), Rac1 ${ }^{\mathrm{f} / \mathrm{fl}}$ and $\mathrm{Cdc} 42^{\mathrm{fl} / \mathrm{fl}}$ mice were crossed with NestinCreER $^{\mathrm{T} 2}$-R26YFP mice (Lagace et al., 2007). All animals used for experiments were heterozygous for the Nestin-CreER ${ }^{\mathrm{T} 2}$ and R26YFP alleles, and those with $\mathrm{Rac1} 1^{\mathrm{fl} / \mathrm{wt}}$ or $\mathrm{Cdc} 42^{\mathrm{fl} / \mathrm{wt}}$ alleles were used as Con for experimental animals with $\operatorname{Racl}^{\mathrm{fl} / \mathrm{fl}}(\mathrm{Racl}-\mathrm{cKO})$ and $\mathrm{Cdc} 42^{\mathrm{fl} / \mathrm{fl}}(\mathrm{Cdc} 42-\mathrm{cKO})$, respectively. Cre-mediated recombination was induced in 6- to 8-weekold adult mice by five consecutive daily intraperitoneal injections of tamoxifen (TAM) (Sigma) at a dosage of $30 \mathrm{mg} / \mathrm{kg}$ (Lagace et al., 2007). Mice were killed at 10,30, and $90 \mathrm{~d}$ after the last TAM injection by transcardial perfusion with cold $4 \%$ paraformaldehyde (PFA). For measuring proliferation in vivo, the $10 \mathrm{~d}$ post-TAM (dpt) group, animals were administered 5-ethynyl-2' -deoxyuridine (EdU) at a dosage of 50 $\mathrm{mg} / \mathrm{kg}, 24 \mathrm{~h}$ before death. Group sizes for all experimental groups were $n \geq 3$.

Immunohistochemistry, immunocytochemistry, and Western blotting. Brains were postfixed overnight at $4^{\circ} \mathrm{C}$ in $4 \%$ PFA and then transferred to $30 \%$ sucrose solution for cryoprotection. Brains were cut coronally on a freezing microtome (Microm), and $40-\mu \mathrm{m}$-thick serial sections were collected in cryoprotectant solution. Tissue for immunostaining was prepared as described previously (Jessberger et al., 2008). Primary antibodies used were chicken $\alpha$-GFP (1:500; Aves Labs), mouse $\alpha$-NeuN (1:100; Millipore), goat $\alpha$-SOX2 (1:500; Santa Cruz Biotechnology), mouse $\alpha$-GFAP (1:500; Sigma), goat $\alpha$-Doublecortin (DCX) (1:250; Santa Cruz Biotechnology), mouse $\alpha$-Racl (1:200; Millipore), chicken $\alpha$-Cdc42 (1:500; Abcam), and rabbit $\alpha$-Ki67 (1:1000; Leica Biosystems). The thymidine analog EdU was used to label dividing cells in vivo and visualized using a staining kit according to the protocol of the manufacturer (Click-iT EdU; Invitrogen). Immunocytochemistry was performed as described above on cells fixed with $4 \%$ PFA for $15 \mathrm{~min}$ at $4^{\circ} \mathrm{C}$. The following primary antibodies were used: chicken $\alpha$-GFP (1:500; Aves Labs), mouse $\alpha$-MAP2ab (1:500; Sigma), and rat $\alpha$-BrdU (1:500; Abcam). Cell nuclei were counterstained with DAPI (1:10,000; Sigma).

Western blotting was performed as described previously (Karalay et al., 2011). Briefly, proteins were separated by electrophoresis in $4-12 \%$ polyacrylamide gels, transferred to nitrocellulose membranes, blocked, and probed overnight at $4^{\circ} \mathrm{C}$. The following primary antibodies were used: mouse $\alpha$-Rac1 (1:1000; Millipore), chicken $\alpha$-Cdc42 (1:1000; Abcam), and mouse $\alpha$-GAPDH (1:10,000; HyTest) primary antibodies. After washes, membranes were incubated with secondary antibodies at 1:5000 dilution: $\alpha$-mouse/chicken conjugated with horseradish peroxidase (Promega) or alkaline phosphatase (Promega) for $2 \mathrm{~h}$ at room temperature. Signal was detected using enhanced chemiluminescence and quantified densitometrically.

Image acquisition and analyses. For colocalization analysis of Cdc 42 and Racl expression and for phenotypic characterization of recombined cells in Cdc42-cKO and Racl-cKO experiments, immunostained sections were imaged using confocal microscopy (Leica SP2 AOBS). Images were acquired with the $20 \times$ objective, and colocalization was analyzed in three dimensions by manual thresholding using Imaris software (Bitplane).

For measuring total dendritic length of retrovirally labeled neurons in vivo, DG images were acquired using the $20 \times$ objective (numerical aperture 0.7 ) on a confocal microscope (Leica SP2 AOBS) at a fixed $Z$-step of $1.5 \mu \mathrm{m}$. $Z$-projections were generated, and total dendritic length was measured in two dimensions using the NeuronJ plugin (Meijering et al., 2004) of NIH ImageJ software (http://imagej.nih.gov/ij/). Individual neuron traces (between 17 and 70 for each genetic condition and time point) made in NeuronJ were used for dendritic arborization analysis using the Sholl analysis plugin in NIH ImageJ (www.ghoshlab.org). For quantifying the length of axonal projections of retrovirally transduced neurons, images of the DG and CA3 region were acquired at $20 \times$ and tiled together using the Stitching plugin in NIH ImageJ (FIJI) (Preibisch et al., 2009). Axonal reach was measured by tracing GFP-positive $\left(\mathrm{GFP}^{+}\right)$axons from the blades of the DG until their visible ends in area CA3 as described previously (Zhao et al., 2006).

For analysis of dendritic spines, images of dendritic segments were acquired using the $63 \times$ objective (numerical aperture 1.4 , zoom 5 ) of the 
A
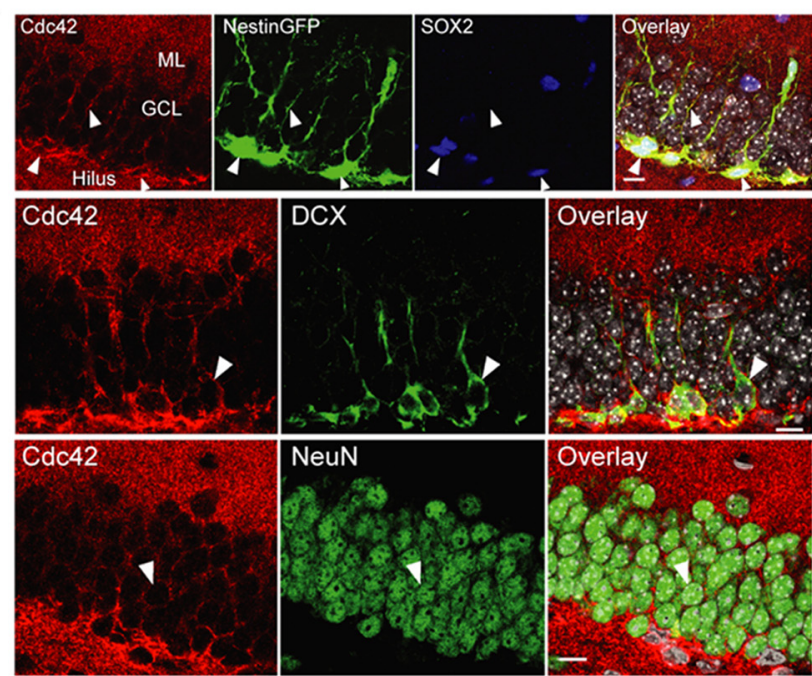

DCX
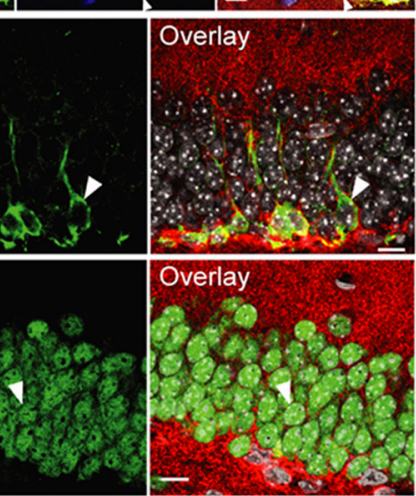

C

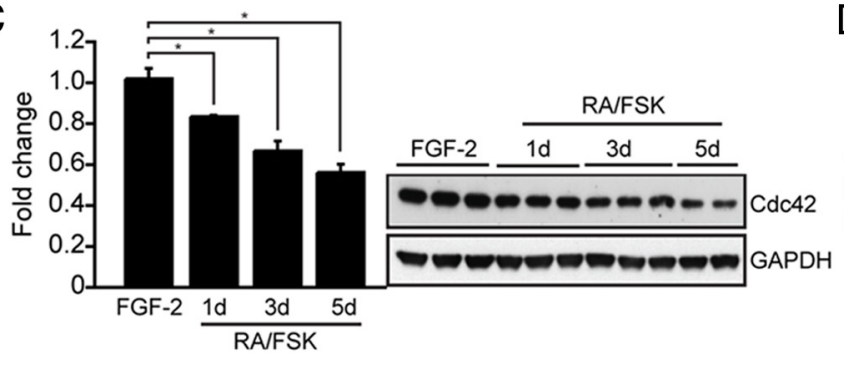

B
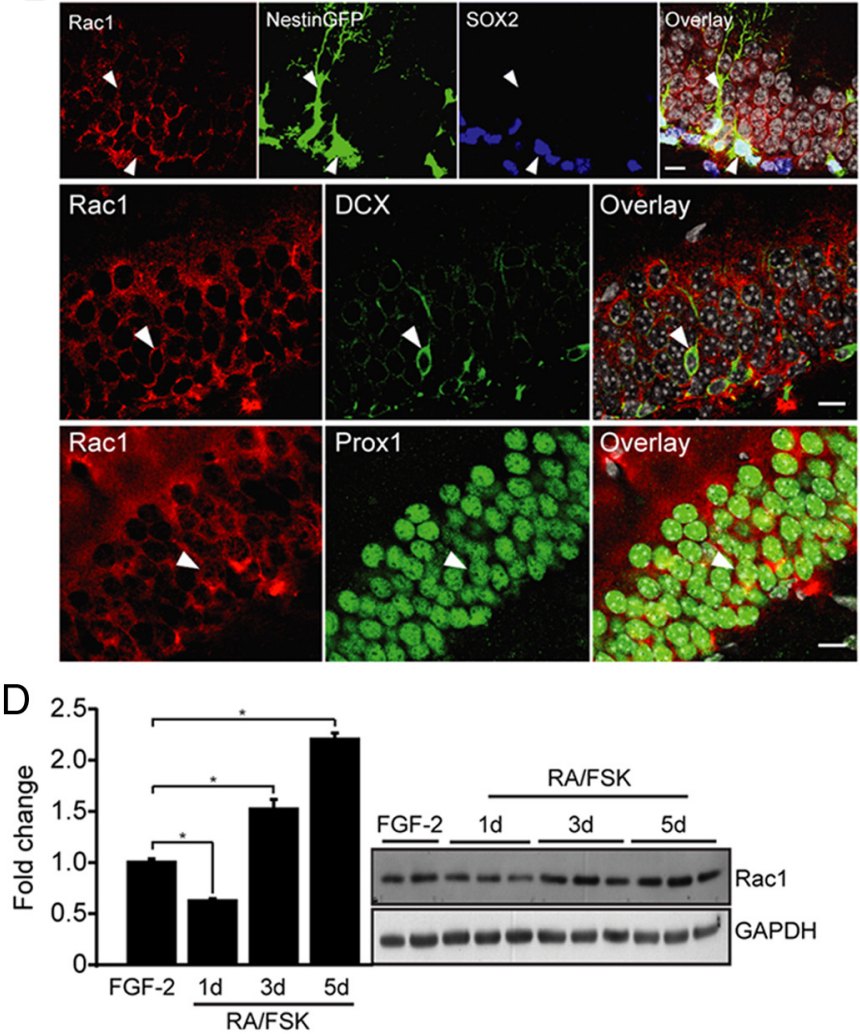

Figure 1. The small Rho GTPases (dc42 and Rac1 are expressed in the adult DG neurogenic niche. $A, C d c 42$ (red) is enriched in SOX2 ${ }^{+}$(blue, top row), NestinGFP ${ }^{+}$(green), and DCX ${ }^{+}$ cells (green, middle row) but also expressed at significant levels in mature NeuN ${ }^{+}$cells (green, bottom row) within the adult DG, indicating that (dc42 is expressed throughout the developmental course of adult neurogenesis but enriched in NSPCs and immature neurons. Arrowheads point toward colabeled cells and Cdc42 expression in processes. $\boldsymbol{B}$, Rac 1 is expressed but not selectively enriched in distinct developmental steps within the neurogenic compartment of the adult DG. Shown is Rac1 expression (red) in NestinGFP ${ }^{+}$(green), SOX2 ${ }^{+}$(blue, top row), and DCX ${ }^{+}$(green, middle row) cells as well as mature Prox ${ }^{+}$granule cells (green, bottom row). Arrowheads point toward colabeled cells and Rac1 expression in processes. All panels on the right show overlay of single channels (with DAPI-stained nuclei, in gray). C, D, In vitro differentiation of adult DG-derived NSPCs by RA/FSK reveals that $\mathrm{Cdc42}(\boldsymbol{C})$ is downregulated with neural differentiation, whereas Rac1 $(\boldsymbol{D})$ is upregulated with differentiation. Shown are representative Western blots and their intensity quantifications for Cdc42 and Rac1, respectively. Data are expressed as mean \pm SEM of fold change over FGF-2 $(n=3)$. Scale bars, $10 \mu \mathrm{m},{ }^{*} p<0.05 . \mathrm{ML}, \mathrm{Molecular} \mathrm{layer.}$

Leica confocal microscope at a constant $Z$-step of $0.2 \mu \mathrm{m}$. Threedimensional images were deconvoluted using Huygens deconvolution software. Analysis of spine density and shape was performed in a semiautomated manner using NeuronStudio software (Dumitriu et al., 2011). Data acquired were collated and analyzed using a custom-made macro in Microsoft Excel.

Statistical analyses. All numerical analyses were performed using Excel (Microsoft) with appropriate add-ons or SPSS Statistics (IBM). For comparisons of averages between two groups, unpaired Student's $t$ test was used. Comparisons between three or more groups were performed using a one-way ANOVA, followed by the Bonferroni's post hoc test for group comparisons. For comparisons between distributions (dendritic length), the Kolomogorov-Smirnov test was used. Differences were considered significant at $p<0.05$.

\section{Results}

Expression of Cdc42 and Racl in the neurogenic lineage of the adult hippocampus

Small Rho GTPases are expressed in many cell types throughout the organism, including neurons of the brain (Govek et al., 2011). To characterize the expression pattern of Cdc42 and Rac1 in the adult DG, we costained brain sections for Rac1 and Cdc42 together with stage-specific markers of neurogenesis (Kempermann et al., 2004). We observed that both Cdc42 and Rac1 were expressed in the neurogenic niche, the subgranular zone, as well as in $\mathrm{NeuN}^{+}$mature granule cells of the DG. Using the NestinGFP reporter line (Yamaguchi et al., 2000) and SOX2 costain- ing, we found that both radial glia-like and non-radial NSPCs expressed Cdc42 and Racl (Fig. 1A,B). Interestingly, we observed an enrichment of Cdc42 in NestinGFP-expressing NSPCs and $\mathrm{DCX}^{+}$immature neurons (Fig. 1A). This was in contrast to Rac1, which was not enriched in Nestin ${ }^{+}$or $\mathrm{DCX}^{+}$cells compared with expression levels in Prox ${ }^{+}$granule cells (Fig. 1B). To further analyze the regulation of $\mathrm{Cdc} 42$ and Rac1 with neural differentiation, we used adult DG-derived NSPC cultures and differentiated them with RA/FSK as described previously (Ray and Gage, 2006). We found Cdc42 to be significantly downregulated during neuronal differentiation, in contrast to Rac1, which was upregulated (Fig. 1C,D). Thus, we found that both Cdc42 and Racl are expressed early on in the neurogenic lineage but that Cdc42 showed a strong enrichment in non-radial NSPCs and immature neurons. Similarly, Cdc42 and Rac1 were differentially regulated with neuronal differentiation in vitro, suggesting that Cdc42 and Rac1 may play distinct roles during the course of adult hippocampal neurogenesis.

\section{Cdc42 and Rac1 are involved in proliferation and neurite} extension of cultured NSPCs

Next, we tested the function of Cdc42 and Rac1 for NSPC proliferation and neuronal differentiation in vitro. We isolated hippocampal NSPCs from adult mice carrying floxed alleles of Rac1 and Cdc42 (Chrostek et al., 2006; Wu et al., 2006). First, we 

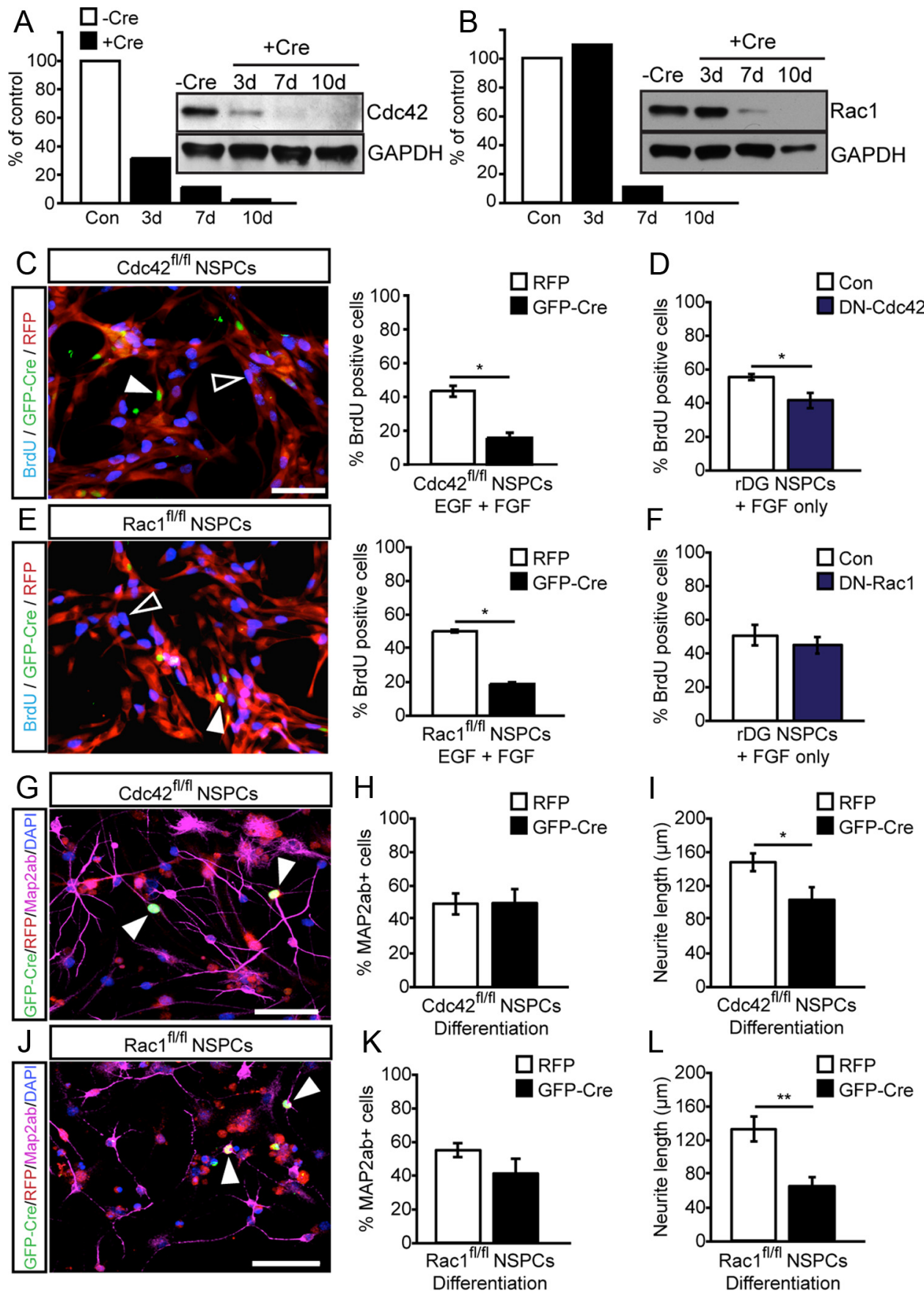

Figure 2. Cdc42 and Rac1 regulate distinct steps in NSPC activity and differentiation in vitro. $\boldsymbol{A}, \boldsymbol{B}$, Mouse hippocampal NSPCs from Cdc42 ${ }^{\mathrm{f} / \mathrm{fl}}$ and Rac $1^{\mathrm{f} / \mathrm{fl}}$ mice were transfected with virally expressed Cre recombinase and cell lysates collected at 3, 7, and $10 \mathrm{~d}$ after transfection. $A$, Cdc42 protein is significantly reduced at 3, 7, and $10 \mathrm{~d}$ after Cre expression. Protein levels are normalized to GAPDH. $\boldsymbol{B}$, Rac1 protein is significantly knocked down by 7 and $10 \mathrm{~d}$ after Cre expression. Shown are Western blots and their intensity quantifications for Cdc42 and Rac1 over GAPDH levels as a percentage of control. C, Retroviral expression of Cre recombinase (GFP, green) leading to genetic deletion of Cdc42 impairs murine NSPC proliferation as measured by BrdU pulse labeling (blue) compared with RFP-expressing control cells (red). Arrowheads point to GFP-Cre-expressing cells negative for BrdU, and open arrowheads point toward RFP/BrdU-labeled cells. Graphs show quantifications. $\boldsymbol{D}$, Overexpression of DN-Cdc42 in rat DG-derived NSPCs phenocopies the effect of Cdc42 deletion on proliferation in mouse NSPCs as measured by BrdU labeling. $\boldsymbol{E}$, Virus-mediated expression of Cre recombinase (GFP, green) deleting Rac1 reduces NSPC proliferation as measured by BrdU pulse labeling (blue) compared with RFP-expressing control cells (red) in mouse NSPCS. Arrowheads point to GFP-Cre ${ }^{+} / \mathrm{BrdU}^{+}$cells, and open arrowheads point toward RFP ${ }^{+} / \mathrm{BrdU}^{+}$cells. Graphs show quantifications. $F$, In contrast, overexpression of DN-Rac1 in rat DG-derived NSPCs does not reduce proliferation of NSPCS as measured by BrdU labeling. G-I, Neuronal differentiation (as measured by MAP2ab expression, purple) of mouse NSPCs after retroviral expression of Cre recombinase (GFP, green) genetically deleting Cdc42 impairs does not the rate of neuronal differentiation but reduces neurite length of in vitro generated NSPC-derived neuronal cells compared with control cells expressing RFP (red). Arrowheads point to GFP-Cre-labeled cells. Quantifications are shown for rate of neuronal differentiation and neurite length. J-L, Similar to the effects of Cdc42 deletion, retrovirus-mediated deletion of Rac1 (GFP, green) in NSPCs does not affect the rate of neuronal differentiation (as measured by MAP2ab expression, purple) but reduces neurite extension compared with control cells expressing RFP (red). Arrowheads point to GFP-Cre ${ }^{+}$cells. Nuclei were counterstained with DAPI. Scale bars, $50 \mu \mathrm{m} .{ }^{*} p<0.05,{ }^{* *} p<0.01$. 

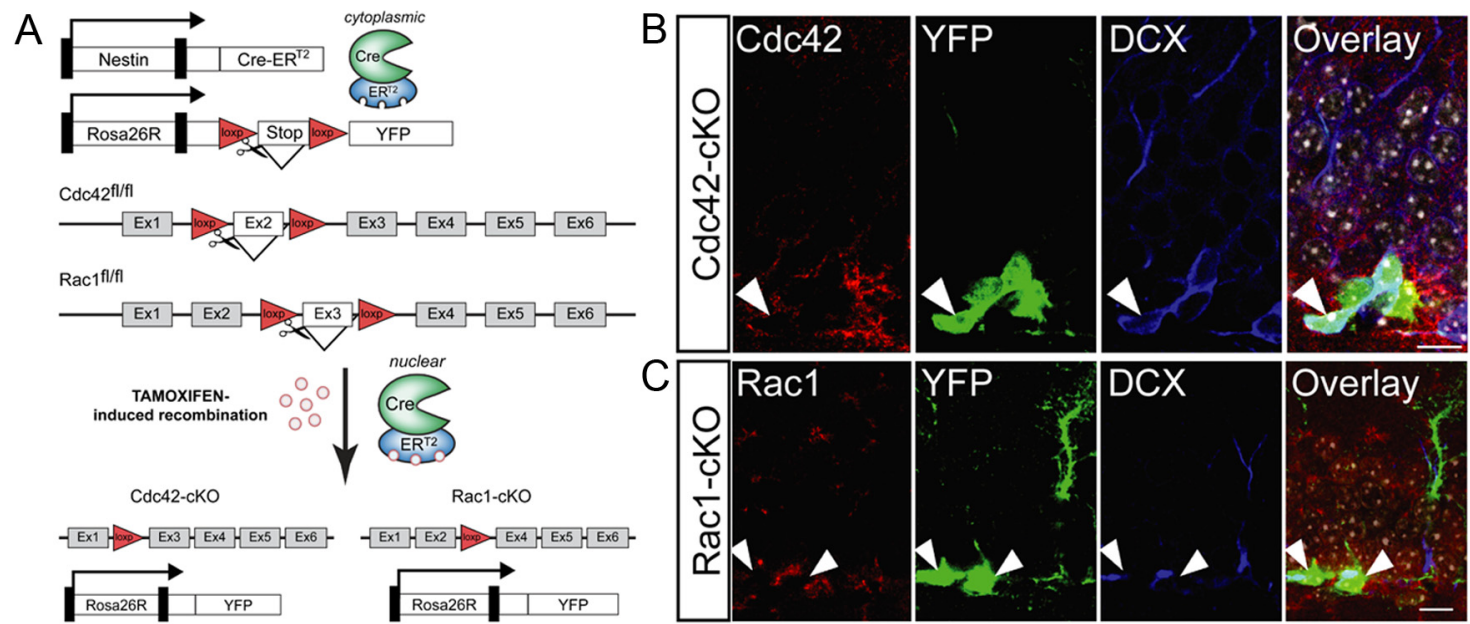

Figure 3. Cre-mediated conditional knockdown of Cdc42 and Rac1 in vivo. $A$, Schematic of genetic strategy to conditionally delete Cdc 42 and Rac1 in NSPCs and their progeny within the adult hippocampus. B, Levels of Cdc42 (red, top row) are reduced in YFP-labeled cells (green) expressing DCX (blue). $\boldsymbol{C}$, In analogy, Rac1 protein expression (red, bottom row) was reduced at $30 \mathrm{dpt}$ in recombined YFP ${ }^{+}$cells. Right panels show overlays of single channels. Scale bars, $10 \mu \mathrm{m}$.

confirmed loss of Cdc42 and Racl protein levels after Cre-based deletion using GFP-Cre-expressing retroviruses. We found a substantial time-dependent decrease of Cdc42 and Racl levels, resulting in an almost complete loss of expression $7 \mathrm{~d}$ after viral transduction (Fig. 2A,B). To assess proliferation, cells were pulsed with the thymidine analog BrdU and fixed $1 \mathrm{~h}$ later after Cre-based genetic deletion of Cdc42 or Rac1. As a complementary approach, we analyzed proliferation of rat NSPCs isolated from the DG of adult rats $3 \mathrm{~d}$ after electroporation with viral constructs expressing the well-characterized DN forms of Rac1 (T17N) and Cdc42 (T17N) (Govek et al., 2005). For Cdc42, we observed a robust reduction of proliferating cells in both murine but also rat NSPCs (Fig. 2C,D). In contrast, we found that Rac1 deletion only led to a reduction of proliferation in mouse NSPCs (that depend on the two growth factors FGF-2 and EGF for proper growth and cell division; Fig. 2E), whereas proliferation in rat NSPCs was not affected after expression of a DN form of Rac1 (Fig. $2 F$ ). These data may indicate that that Racl is specifically involved in EGF-dependent growth of adult NSPCs, although species-dependent differences may also account for the observed effects.

Cdc42 or Rac1 deletion did not increase the amount of cell death in cultured NSPCs as measured by analyzing the number of TUNEL $^{+}$cells (data not shown). We next analyzed whether deletion of Cdc42 and Rac1 affects neuronal fate determination and/or neuronal maturation of cultured NSPCs. Again, we used retroviruses expressing Cre recombinase to delete Cdc42 and Rac1, respectively. Whereas the rate of neuronal differentiation, as measured by the expression of MAP2ab, was not altered after Cdc42 or Rac1 deletion (Fig. $2 G, H, J, K$ ), we found a striking decrease in the total length of neurites extending from Cdc42and Racl-deficient neuronal cells (Fig. 2I,L), suggesting that small Rho GTPase signaling mediated by Cdc 42 and Racl is involved in neuronal maturation/neurite extension of neuronal cells generated by NSPCs in vitro.

\section{Genetic deletion reveals stage-specific function of $\mathrm{Cdc} 42$ for NSPC proliferation}

To assess functional roles for Racl and Cdc42 in adult neurogenesis directly in vivo, we sought to genetically delete Racl and Cdc42 selectively in adult hippocampal NSPCs and their progeny. To this end, we again used mice carrying floxed alleles of
Rac1 and Cdc42 (Chrostek et al., 2006; Wu et al., 2006) that were crossed with transgenic mice expressing a TAM-inducible Cre recombinase under the Nestin promoter that is active in adult hippocampal NSPCs (Lagace et al., 2007). To visualize recombined cells, the triple transgenic mice also harbored a yellow fluorescent protein (YFP)-expressing ROSA reporter (hereafter called Cdc42-cKO and Rac1-cKO) (Fig. 3A). Adult Cdc42cKO, Racl-cKO, and respective control mice received repeated TAM injections to induce recombination and were killed at different time points after the last TAM injection. First, we confirmed the loss of Cdc42 and Racl protein in vivo using mice harboring floxed alleles of $\mathrm{Cdc} 42$ or Rac1 after Cre-mediated genetic deletion at $30 \mathrm{dpt}$ (Fig. $3 \mathrm{~B}, \mathrm{C}$ ).

To label proliferating cells after genetic deletion of $\mathrm{Cdc} 42$ and Racl at the $10 \mathrm{~d}$ time point, animals were injected with the thymidine analog EdU $24 \mathrm{~h}$ before they were killed. At $10 \mathrm{dpt}$, we found that deletion of Cdc42 substantially reduced the percentage of EdU ${ }^{+} / \mathrm{YFP}^{+}$cells of all $\mathrm{YFP}^{+}$, recombined cells in Cdc42cKO compared with control mice (Con, $6.47 \pm 0.94$; Cdc42cKO, $2.23 \pm 0.61$ ), indicating that $\mathrm{Cdc} 42$ is critically involved in the proliferation of adult hippocampal NSPCs (Fig. 4A,B). A similar effect on NSPC proliferation, as measured by the number of YFP ${ }^{+}$cells that colabeled with the cell cycle marker Ki67 (Fig. $4 C$ ), was observed at a later time point after Cdc42 deletion (30 $\mathrm{dpt}$ ). However, we found no differences in the relative number of EdU-labeled cells that expressed Ki67, suggesting that cell cycle dynamics or reentry had not substantially changed after Cdc 42 deletion (data not shown). Recombined cells at each time point were phenotyped and categorized as radial NSPCs (radial morphology, $\mathrm{GFAP}^{+} / \mathrm{SOX}^{+}{ }^{+}$), non-radial NSPCs (non-radial morphology, $\mathrm{GFAP}^{-} / \mathrm{SOX}^{+}{ }^{+}$), or neurons (neuronal morphology, $\mathrm{GFAP}^{-} / \mathrm{SOX}^{-}$). At both the 10 and $30 \mathrm{~d}$ time points, no significant differences were observed in the cell-fate distribution of recombined cells, suggesting that neuronal differentiation itself was not affected (Fig. $4 K$ ). Interestingly, although the percentage of proliferating cells were significantly lower in $\mathrm{Cdc} 42-\mathrm{cKO}$ mice at the 10 and $30 \mathrm{dpt}$ time points, this was not reflected by the total number of YFP ${ }^{+}$cells (Fig. $4 D, E$ ). Given that only a small percentage of recombined cells were dividing at a given time point ( $\sim 4-7 \%$; Fig. $4 B, C)$, it is possible that several rounds of division would be required before an effect on the total number of neurons could be observed. To address this, we performed an exper- 

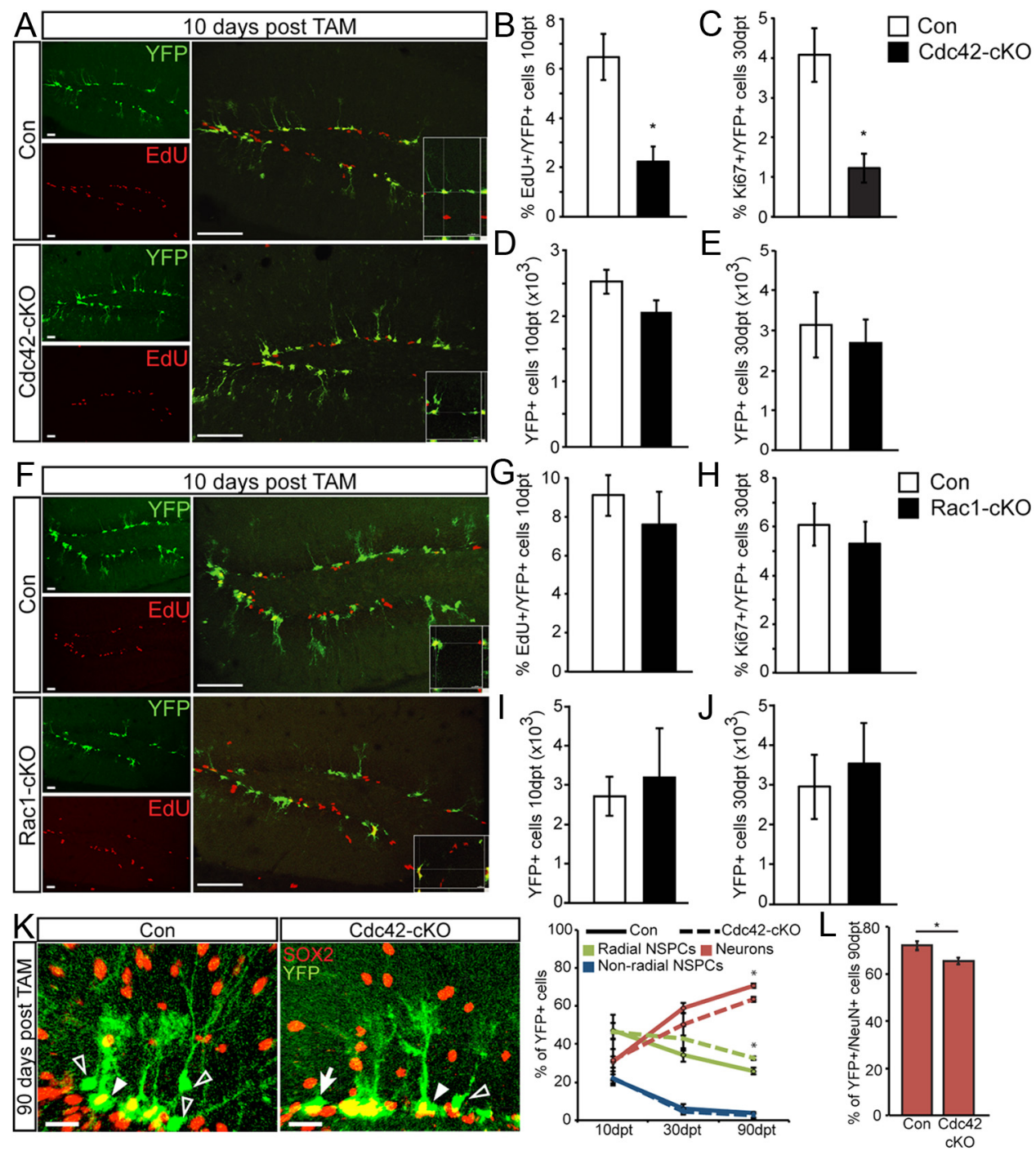

Figure 4. Loss of Cdc42 but not Rac1 decreases proliferation of NSPCs and impacts adult hippocampal neurogenesis. $A$, Cdc42-cKO cells expressing YFP (green) have significantly reduced proliferation $10 \mathrm{dpt}$-induced recombination as measured by EdU pulse labeling (red). Right columns show overlays for control (top row) and (dc42-cKO (bottom row). Insets show threedimensional reconstructions confirming EdU labeling in a subset of YFP-labeled cells. $\boldsymbol{B}$, $\boldsymbol{C}$, Shown are quantifications of YFP-expressing cells colabeled with EdU at $10 \mathrm{dpt}(\boldsymbol{B})$ and the endogenous cell cycle marker Ki67 at $30 \mathrm{dpt}(\boldsymbol{O})$. D, E, The total number of recombined YFP ${ }^{+}$cells was not changed in Cdc42-cK0 mice compared with control at the $10 \mathrm{dpt}(\boldsymbol{D})$ and $30 \mathrm{dpt}(\boldsymbol{E})$ time points. $\boldsymbol{F}$-J, In contrast to Cdc42 deletion, $C K 0$ of Rac1 does not affect NSPC proliferation at $10 \mathrm{dpt}$; representative images show YFP-labeled cells (green) colabeled with EdU (red, $\boldsymbol{F}, \boldsymbol{G}$ ) or at $30 \mathrm{dpt}$ as measured with Ki67 labeling $(\boldsymbol{H})$. In addition, Rac1-cK0 does not affect the total number of YFP-labeled cells at $10 \mathrm{dpt}(\boldsymbol{I})$ or $30 \mathrm{dpt}(\boldsymbol{J})$. $\boldsymbol{K}, \boldsymbol{L}$, Quantification of the phenotype of recombined cells in $(\mathrm{d} c 42-\mathrm{cKO}$ at $90 \mathrm{dpt}$ indicates a decrease in YFP-labeled cells displaying neuronal morphology (open arrowhead in $K$ ) that are negative for SOX2 and GFAP (Con, 70.8 $\pm 1.2 ;(\mathrm{Cdc}-\mathrm{CK} 0,63.6 \pm 1.3 \%)$. In analogy, there is a decrease in YFP ${ }^{+} / \mathrm{NeuN}^{+}$cells $(\boldsymbol{L})$. At the same time, deletion of (dc42 leads to an increase of radial glia-like NSPCs [right, arrowhead points toward a YFP ${ }^{+}$(green)/SOX2 ${ }^{+}$(red) cell] (Con, $25.8 \pm 1.8 ; \mathrm{Cdc}-\mathrm{cKO}, 32.7 \pm 1.0 \%$ ) and no change in non-radial NSPCs [right, arrow points toward a YFP ${ }^{+}$(green)/SOX2 ${ }^{-}$(red) non-radial cell]. Right graph shows quantifications of different phenotypes at 10,30, and $90 \mathrm{dpt}$ and the percentage of $\mathrm{YFP}^{+} / \mathrm{NeuN}^{+}$neurons at $90 \mathrm{dpt}$ in $\mathrm{Cdc} 42-c K 0$. Data are expressed as mean \pm SEM ( $n=3-6$ per group). Scale bars: $A, F, 40 \mu \mathrm{m}$; K, $20 \mu \mathrm{m} .{ }^{*} p<0.05$.

iment in which animals were killed at $90 \mathrm{dpt}$ and quantified the phenotypic distribution of recombined cells. Quantification revealed a significant reduction in the percentage of recombined cells turning into neurons (as measured by the number of $\mathrm{YFP}^{+} /$ $\mathrm{NeuN}^{+}$cells) in Cdc42-cKO mice compared with control with a concurrent increase in the percentage of radial glia-like NSPCs, indicating a reduction in total neurogenesis after $\mathrm{Cdc} 42$ deletion (Fig. $4 K, L$ ). These data show that loss of Cdc42 causes a reduction in NSPC proliferation and an eventual loss of adult-born neurons in the DG.

In striking contrast to the effects of Cdc42 deletion on adult NSPCs, we found no significant differences in proliferation after conditional Racl deletion at both the 10 and $30 \mathrm{~d}$ time points after TAM (Fig. 4F, G,I). There was no change in the total num- ber of recombined cells at both time points (Fig. $4 H, J$ ). There were also no significant differences in the phenotypic distribution of recombined cells in Racl-cKO mice (data not shown). These results illustrate that $\mathrm{Cdc} 42$ plays an important role in the proliferation of adult hippocampal NSPCs, whereas Rac1 does not appear to be critically involved in this step during the course of adult neurogenesis.

Cdc42 is required for early and late steps of dendritic growth, whereas Racl is only involved in late steps of dendritic maturation

Adult-born hippocampal neurons go through distinct stages of morphological development as they go from immature neurons to mature granule cells and integrate into the dentate circuitry 

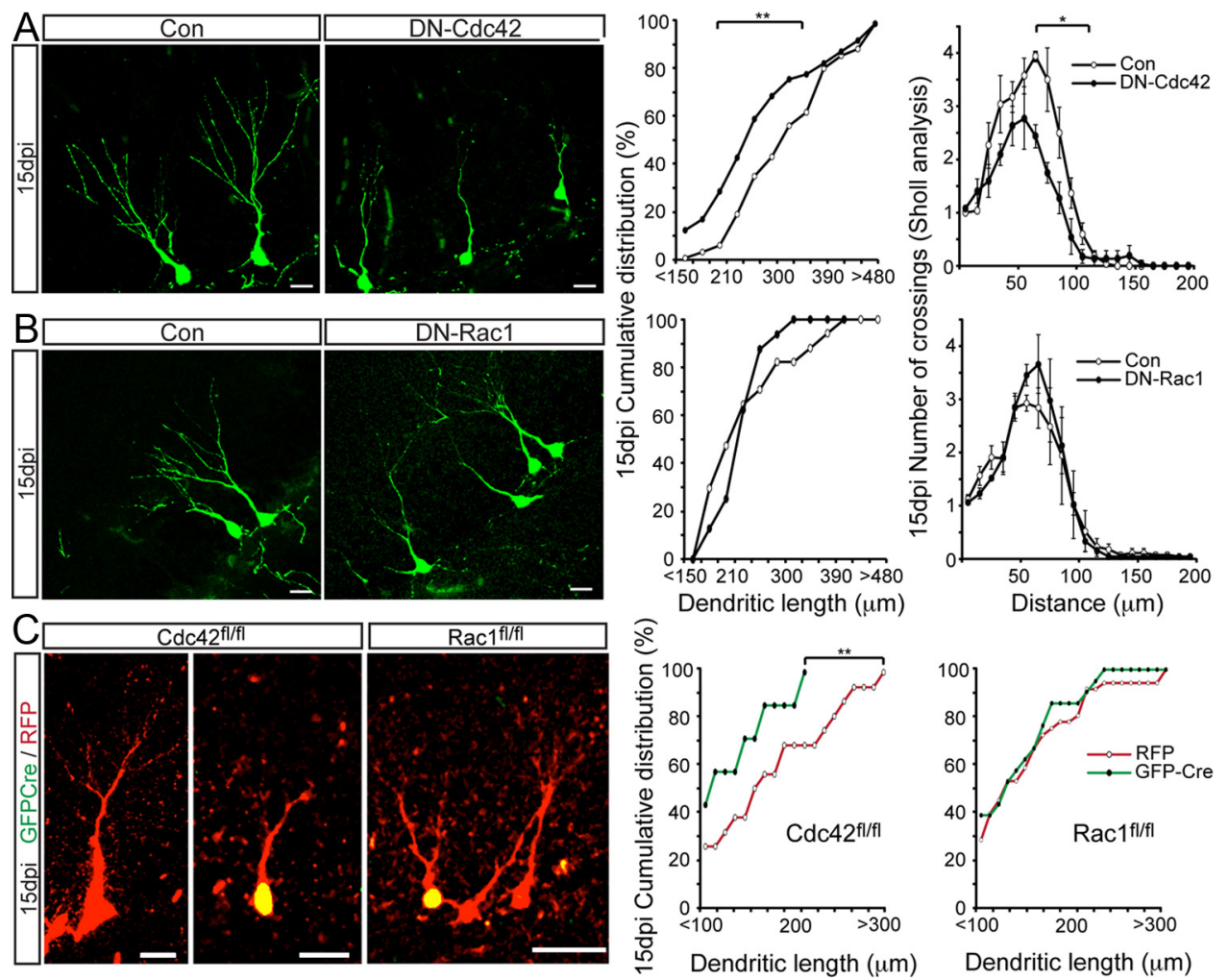

Figure 5. Selective impairment of dendritic growth with impaired activity of Cdc42 but not with Rac1. A, Overexpression of DN-Cdc42 impairs dendritic maturation of newborn neurons 15 dpi. Shown are representative images of retrovirally labeled control cells (Con, green) or DN-Cdc42 (green). Distribution of dendritic lengths and branching are shown on the right. DN-Cdc42-expressing cells have significantly shorter dendrites (Con, 318.2 \pm 8.75; DN-Cdc42, $226.6 \pm 5.2 \mu \mathrm{m}$ ) and a reduced number of dendritic branching points (Con, 6.75 \pm 0.6 ; DN-Cdc42, 3.9 \pm 0.28 ). $\boldsymbol{B}$, DN-Rac1-overexpressing cells (green) are not significantly different from control (green) in dendritic length measurements (Con, 250 $\pm 29 ; \mathrm{DN}-\operatorname{Rac1} 240 \pm 13.3 \mu \mathrm{m}$ ) or in branching (Con, $5 \pm$ 0.7; DN-Rac1, $4.4 \pm 0.24) 15 \mathrm{~d}$ after injection of viruses, suggesting that only $\mathrm{Cd}(42$ but not Rac1 is important for early dendritic growth. Data are expressed as mean or cumulative distribution \pm SEM ( $n=3-4$ per group). C, Cell-autonomous genetic deletion of $\mathrm{Cdc} 42$ and Rac1 phenocopies the effects using DN forms of $\mathrm{Cdc} 42$ and Rac1. Cdc42 ${ }^{\mathrm{fl} / \mathrm{fl}}$ and Rac $1^{\mathrm{fl} / \mathrm{fl}}$ mice were injected with a retrovirus mix expressing RFP (red) and GFP-Cre (green) and killed at $15 \mathrm{dpi}$. GFP-Cre ${ }^{+} / \mathrm{RFP}^{+}$cells in Cdc42 $2^{\mathrm{fl} / \mathrm{fl}}$ mice had significantly shorter dendrites and reduced branching compared with RFP-only-expressing control cells at $15 \mathrm{dpi}$ (C, left) (dendritic length: RFP, $154 \pm 12.6$; GFP-Cre, $112 \pm 8.8 \mu \mathrm{m}$ ). In contrast to $\left(\mathrm{d} C 42\right.$ deletion, (re-based recombination in Rac1 ${ }^{\mathrm{f} / \mathrm{fl}}$ mice $(C$, right panels) did not affect dendritic growth (dendritic length: RFP, $164.5 \pm 26.4$; GFP-Cre, $122.4 \pm 39.4 \mu \mathrm{m}$ ). Quantifications are shown in the right graphs. Data are expressed as mean or cumulative distribution \pm SEM ( $n=3-4$ per group). Scale bars: $A, B, 15 \mu \mathrm{m} ; \boldsymbol{C}, 30 \mu \mathrm{m} .{ }^{*} p<0.05,{ }^{* *} p<0.01$.

(Zhao et al., 2006). Axons extending from newborn granule cells project to area CA3, whereas their dendrites arborize into the molecular layer of the DG. Although extrinsic factors have been shown to modulate the morphological maturation of NSPCs, intrinsic pathways governing neuronal morphology are now beginning to emerge (Zhao et al., 2008). Previous studies have shown that small Rho GTPases govern cell morphology and neurite outgrowth in vitro and during embryonic development (Govek et al., 2005). Hence, we next sought to address whether Cdc42 and Racl play a role in the morphological maturation of adult-born neurons in vivo. Although conditional deletion of Cdc42 and Rac1 in NSPCs using Nestin-Cre-ER ${ }^{\mathrm{T} 2}$ mice allowed us to explore their function in proliferation and cell-fate choice on a population level, the relative weakness of YFP expression driven by the ROSA promoter and the high density of recombined cells hampers a thorough analysis of neuronal morphology. To address the cell-autonomous functions of Cdc42 and Rac1 in later steps of neuronal maturation, we used a retrovirus-based approach. We used the DN forms of Racl (T17N) and Cdc42 (T17N) (Govek et al., 2005). Using retrovirus-based delivery, we overexpressed DN-Racl and DN-Cdc42 in newborn cells of the adult DG. Animals were killed 15 and 30 dpi. At 15 dpi, when newborn neurons are still in immature stages (Zhao et al., 2006), we found that DN-Cdc42-overexpressing neurons had significantly shorter dendrites and reduced dendritic arborization com- pared with control cells (Fig. 5A). In contrast, DN-Rac1overexpressing neurons at $15 \mathrm{dpi}$ were not significantly different from control cells in either total dendritic length or branching (Fig. 5B).

$\mathrm{DN}$ forms of Cdc42 and Racl have been used extensively to study their functional roles and have proved to be powerful tools to dissect their functions. However, there are certain caveats to this approach, such as off-target effects and activity-based compensation. Hence, we confirmed our findings using a retrovirusbased genetic deletion approach in vivo. To delete Cdc42 and Racl selectively in newborn cells, adult transgenic mice $\left(\mathrm{Cdc} 42^{\mathrm{fl} / f \mathrm{ll}}\right.$ and $\left.\mathrm{Racl}{ }^{\mathrm{fl} / \mathrm{fl}}\right)$ were stereotactically injected with retrovirus expressing GFP-Cre together with RFP-expressing control virus. Animals were killed at $15 \mathrm{dpi}$, and double-labeled $\mathrm{KO}$ cells $\left(\mathrm{GFP}-\mathrm{Cre}^{+} / \mathrm{RFP}^{+}\right)$were compared with control cells $\left(\mathrm{RFP}^{+}\right.$ only) in the same DG (Tashiro et al., 2006). Corroborating our findings with DN-Cdc42 and DN-Racl overexpression at $15 \mathrm{dpi}$, we observed a selective impairment in dendritic maturation attributable to genetic loss of Cdc42 but not Rac1, suggesting a stage-specific function for these Rho GTPases in neuronal maturation (Fig. 5C).

We next assessed neuronal morphology at $30 \mathrm{dpi}$, a time point by which neurons are functionally integrated into the DG circuitry and receive input from the entorhinal cortex and also generate output toward cells in the hilus and CA3 (Toni et al., 2007; 

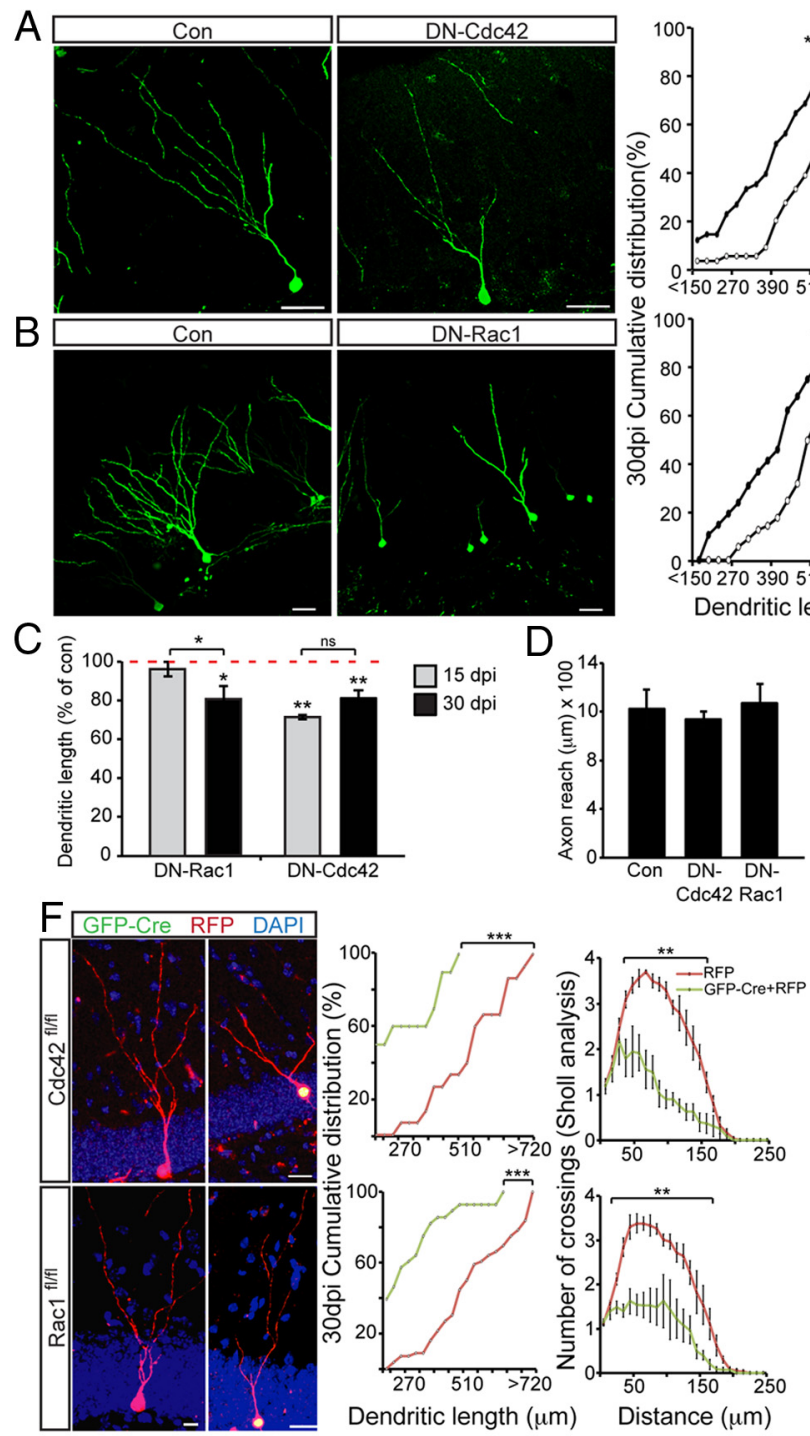
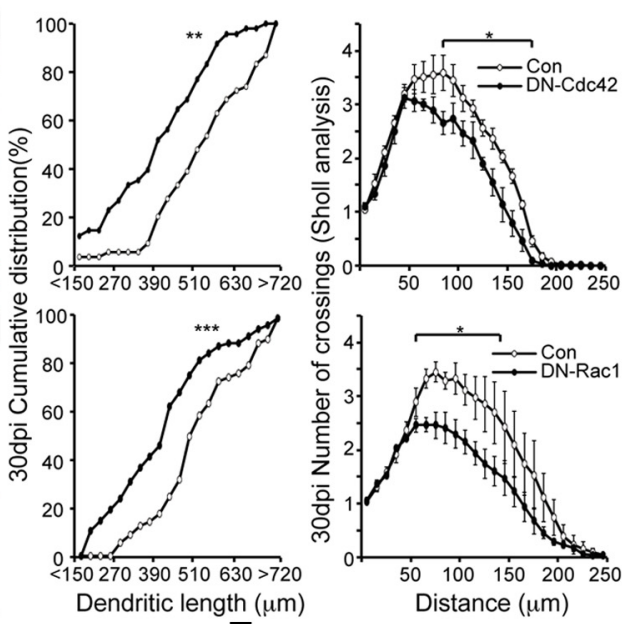

$\mathrm{E}$

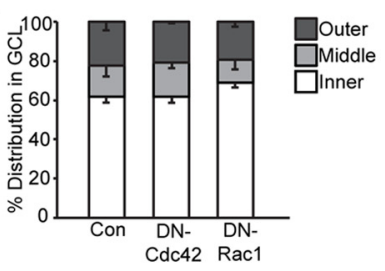

G
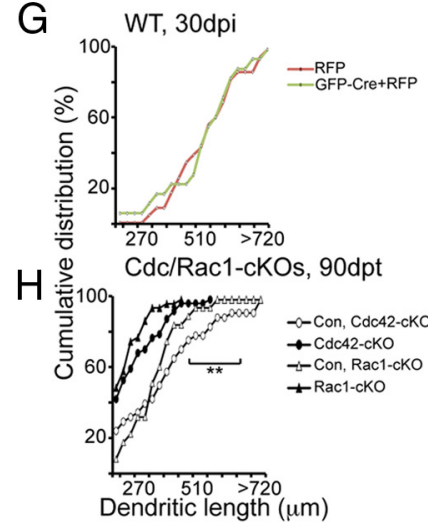

Figure 6. Virus-based knockdown and conditional deletion of $\mathrm{Cdc} 42$ and Rac1 impairs dendritic growth at later stages of neuronal development. $A, D N-C d c 42$ leads to a significant reduction of dendritic growth (Con, 520.4 \pm 19.3; DN-Cdc42,391.1 $\pm 19 \mu \mathrm{m}$ ) and branching (Con, 5.4 \pm 0.37; DN-Cdc42, $3.68 \pm 0.21$ ) at 30 dpi. B, DN-Rac1 overexpression impairs dendritic growth (Con, $523.1 \pm 23 ; \mathrm{DN}-\mathrm{RaC1}, 388.4 \pm 31.5 \mu \mathrm{m}$ ) and arborization (Con, $4.9 \pm 0.2 ; \mathrm{DN}-$ Rac1, 3.6 \pm 0.3 ) at $30 \mathrm{dpi}$. Shown on the left are representative images of retrovirally labeled neurons at $30 \mathrm{dpi}$, and on the right are the distribution of dendritic lengths and branching. $C$, Comparisons of the averages of dendritic lengths expressed as a percentage of their respective control confirm that knockdown of Rac1 activity specifically impairs dendritic growth specifically at 30 dpi, whereas Cdc42 activity knockdown affects dendritic growth at both time points. Axon outgrowth into area $C A 3$ (Con, 1222 \pm 159; DN-Cdc42, $1140 \pm 63 ; \mathrm{DN}-\operatorname{Rac1}, 1261 \pm 157 \mu \mathrm{m})$ (D) and localization within the GCL are not affected by knockdown of Cdc42 or Rac1 activity 30 dpi (E). $\boldsymbol{F}$, Cell-autonomous genetic deletion of $\mathrm{Cdc} 42$ and Rac1 phenocopies impaired dendritic growth and maturation of adult-born neurons as observed using DN forms of $\mathrm{Cdc} 42$ and Rac1. $\mathrm{Cdc4}{ }^{\mathrm{fl} / \mathrm{fl}}$ and Rac $1^{\mathrm{fl} / \mathrm{fl}}$ mice were injected with a retrovirus mix expressing RFP (red) and GFP-Cre (green). GFP-Cre ${ }^{+} / \mathrm{RFP}^{+}$cells had significantly shorter dendrites and reduced branching compared with RFP-only-expressing control cells at 30 dpi in both Cdc42 ${ }^{\mathrm{f} / \mathrm{fl}}$ ( $\boldsymbol{F}$, top row) (dendritic length: RFP, $512 \pm 15$; GFP-Cre, $221 \pm 13.8 \mu \mathrm{m}$; branching: RFP, $6.6 \pm 0.1$; GFP-Cre, 3.8 \pm 0.6$)$ and Rac1 ${ }^{\mathrm{f} / \mathrm{fl}}$ (F, bottom row) (dendritic length: RFP, 518.8 $\pm 35.7 ;$ GFP-Cre, $266.1 \pm 38 \mu \mathrm{m}$; branching: RFP, $5.7 \pm 0.4 ;$ GFP-Cre, $3.2 \pm 0.8$ ) mice. Quantifications are shown in the right graphs. Data are expressed as mean or cumulative distribution \pm SEM ( $n=3-4$ per group). G, Prolonged (30 dpi) virus-mediated Cre expression does not impair dendritic growth in wild-type mice. $\boldsymbol{H}$, Genetic loss of Rac1 and Cdc42 leads to reduced dendritic length at $90 \mathrm{dpt}$ in recombined, YFP-labeled cells compared with their respective control. Scale bars: $\boldsymbol{A}, \boldsymbol{B}, 30 \mu \mathrm{m} ; \boldsymbol{F}, 10 \mu \mathrm{m} .{ }^{*} p<0.05$, ${ }^{* *} p<0.01$, ${ }^{* * *} p<0.001$.

Toni et al., 2008). Similar to what was observed at $15 \mathrm{dpi}$, DNCdc42 overexpression led to a reduction in dendritic length and branching at $30 \mathrm{dpi}$ (Fig. 6A). Interestingly, in contrast to what was observed at $15 \mathrm{dpi}$, DN-Rac1-overexpressing neurons now also had significantly shorter dendrites and reduced branching at 30 dpi (Fig. 6B), suggesting that Rac1 specifically regulates late steps of neuronal growth/maturation. To compare differences between dendritic lengths of DN-Racl- and DN-Cdc42expressing neurons at the two different time points, we normalized individual dendritic length values as percentages of their respective Con and compared these percentages. These calculations showed that DN-Racl overexpression led to a specific re- duction in dendritic length from 15 to 30 dpi. In comparison, there were no significant differences in dendritic length reduction between 15 and $30 \mathrm{dpi}$ in the DN-Cdc42 group (Fig. $6 \mathrm{C}$ ). Together, these results indicate stage-specific roles for $\mathrm{Cdc} 42$ and Rac1 in the maturation of adult-born granule cells: Cdc42 is involved in early and late steps of dendritic growth, whereas Rac1 appears to be selectively involved in later steps of dendritic maturation.

We next sought to test whether Cdc42 and Racl are also important for growth and proper targeting of axonal processes extending from newborn granule cells toward area CA3. Axon coverage was quantified by measuring the distance traversed by 

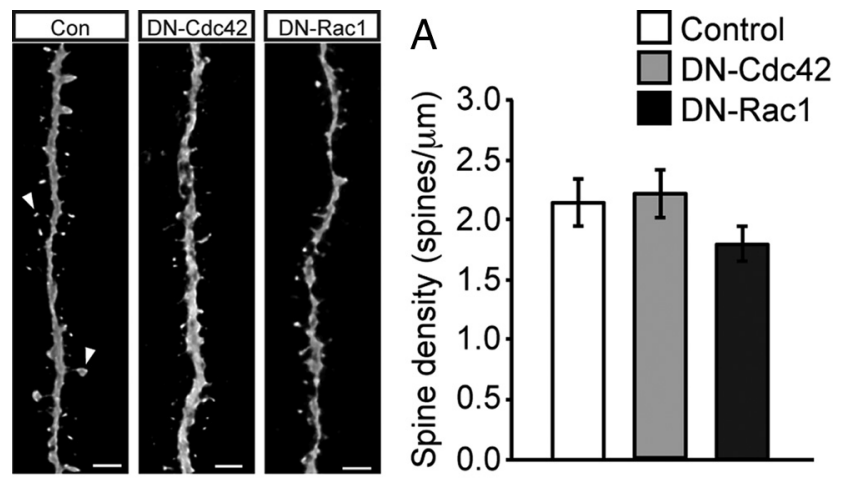

B

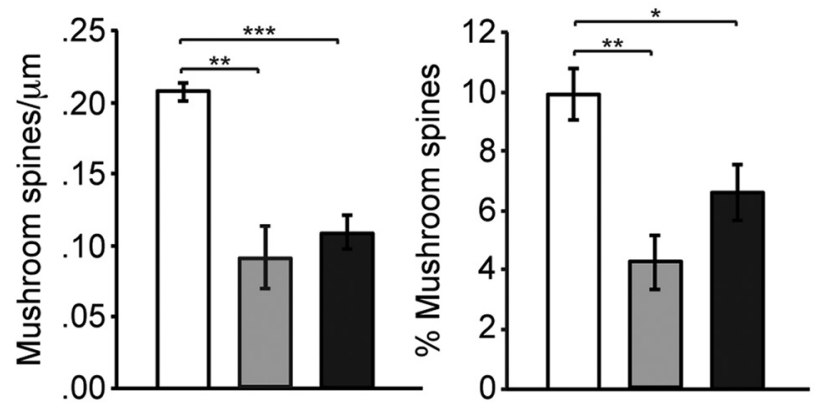

Figure 7. Overexpression of DN-Cdc42 and DN-Rac1 impairs dendritic spine maturation. $\boldsymbol{A}$, Total spine density was not significantly affected by DN-Cdc42 or DN-Rac1 expression compared with GFP-expressing control at $30 \mathrm{dpi}$ (total spine density: Con, $2.14 \pm 0.2, \mathrm{DN}-\mathrm{Cdc} 42$, $2.2 \pm 0.2 ; \mathrm{DN}-\operatorname{Rac1}, 1.79 \pm 0.15) . \boldsymbol{B}, \boldsymbol{C}$, The density and relative percentage of mushroomshaped spines was significantly reduced in DN-Cdc42- and DN-Rac1-expressing cells compared with cells expressing a control virus (mushroom spine density: Con, $0.21 \pm 0.01 ; \mathrm{DN}-$ Cdc42, $0.09 \pm 0.02$; DN-Rac1, $0.11 \pm 0.01$; percentage: Con, $9.91 \pm 0.86 \%$; DN-Cdc42, $4.2 \pm 0.92 \%$; DN-Rac1, $6.6 \pm 0.93 \%$ ), suggesting that spine maturation but not spine initiation is affected by both $\mathrm{Cdc} 42$ and Rac1 knockdown. Shown are representative images of dendritic spines (arrowheads indicate mushroom spines). Data are expressed as mean \pm SEM ( $n=3-4$ per group). Scale bars, $2 \mu \mathrm{m} .{ }^{*} p<0.05,{ }^{* *} p<0.01,{ }^{* *} p<0.001$.

$\mathrm{GFP}^{+}$axon tracts from the edge of the DG to the extent of the CA3 region at $30 \mathrm{dpi}$ (Zhao et al., 2006). We found that axonal tracts of retrovirally labeled cells indeed reached the CA3 region of the hippocampus and that this was not discernibly influenced by DN-Cdc42 and DN-Racl overexpression compared with control (Fig. 5D).

Previous studies have indicated that $\mathrm{Cdc} 42$ and Rac1 regulate cell motility and migration (Fukata et al., 2003). Therefore, we quantified whether overexpression of DN-Cdc42 or DN-Rac1 influenced the migration of newborn neurons into the granule cell layer (GCL) of the DG at $30 \mathrm{dpi}$. Confirming previous data, we observed that a vast majority of adult-born neurons remain in the inner part of the GCL (Fig. 5E) (Duan et al., 2007). Notably, overexpression of DN-Cdc42 or DN-Racl did not influence the distribution of adult-born neurons in the DG GCL (Fig. 5E).

Next, we sought to confirm our findings at the 30 dpi time point again using a retrovirus-based genetic deletion approach in vivo. $\mathrm{Cdc} 42^{\mathrm{fl} / \mathrm{fl}}$ and $\mathrm{Rac} 1^{\mathrm{fl} / \mathrm{fl}}$ mice were stereotactically injected with retrovirus expressing GFP-Cre together with RFPexpressing control virus. Animals were killed at $30 \mathrm{dpi}$, and double-labeled $\mathrm{KO}$ cells $\left(\mathrm{GFP}-\mathrm{Cre}^{+} / \mathrm{RFP}^{+}\right.$) were compared with control cells ( $\mathrm{RFP}^{+}$only) in the same DG. With this approach, we confirmed the DN-Rac1- and DN-Cdc42-based findings because Cre-expressing cells in $\mathrm{Cdc} 42^{\mathrm{fl} / \mathrm{fl}}$ and $\mathrm{Rac1}{ }^{\mathrm{fl} / \mathrm{fl}}$ animals had significantly shorter dendrites and reduced dendritic branching at higher orders, compared with RFP-only-expressing control cells
(Fig. 6F). To control for potential effects of prolonged Cre expression for dendritic development, we injected wild-type mice with Cre-expressing retroviruses together with RFP control viruses. However, we found no effect of Cre expression when we analyzed dendritic development at $30 \mathrm{dpi}$ in wild-type mice (Fig. 6G).

Next, we analyzed whether deletion of Cdc42 or Rac1 may simply cause a delay in dendritic maturation. To address this, we analyzed dendritic morphology at $90 \mathrm{dpt}$ using Cdc42-cKO and Racl-cKO mice. Strikingly, we found that dendritic length was reduced for both $\mathrm{Cdc} 42-$ and Rac1-deficient newborn neurons even 90 after genetic deletion (Fig. 6H). These results suggest that the observed defects in dendritic complexity are likely not attributable to a delay in dendrite growth and indicate a crucial role for Cdc42 and Rac1 in dendritic maturation of adult-born granule cells.

Together, these results obtained by two complementary methods (DN and genetic loss of function) indicate that Cdc42 is critical for early and late steps of dendritic development, whereas Racl has a predominantly late role in dendritic extension and maturation.

\section{Rac1 and Cdc42 activity knockdown impairs dendritic spine maturation of adult-born neurons}

As they mature, adult-born hippocampal neurons start receiving excitatory input from the entorhinal cortex and get integrated into the DG circuitry. This excitatory input is thought to be important for the survival and integration of adult-born neurons. Specialized protrusions from the dendritic shaft, known as dendritic spines, are the postsynaptic sites for incoming excitatory input. Spines are dynamic structures, and their density and shape are thought to be indicative of excitatory integration of neurons. $\mathrm{Racl}$ and Cdc42 are known to localize to dendritic spines and regulate their motility in primary hippocampal neurons in vitro (Tashiro and Yuste, 2004; Murakoshi et al., 2011). Hence, we next asked whether Cdc42 and Racl were important for spine morphogenesis and excitatory integration of newborn neurons in vivo. To address this question, we analyzed dendritic spines of retrovirally labeled neurons overexpressing DN-Cdc42 and DN$\mathrm{Racl}$ at $30 \mathrm{dpi}$. We found that overexpression of DN-Cdc42 or DN-Racl did not influence total spine density compared with Con (Fig. 7A). However, the density and percentage of mushroom-shaped spines was significantly lower in both DNCdc42- and DN-Rac1-overexpressing neurons compared to control cells (density: Con, $0.21 \pm 0.01 ; \mathrm{DN}-\mathrm{Cdc} 42,0.09 \pm 0.02$; DN-Rac1, $0.11 \pm 0.01$ ) (Fig. 7 B, C). Mushroom spines represent the more mature population of spines, and their large head/neck ratio is thought to contribute to their function as stable excitatory synapses. Given that there were no differences in the total density of spines, specific alterations in the fraction of mushroom spines may reflect impairment in synaptic integration of these neurons. Our results demonstrate that the Rho GTPases Cdc42 and Rac1 may not be crucial for the initiation and formation of spines, but appear to be critical for spine maturation and stabilization as observed by the reduction in the density of mushroom spines.

\section{Discussion}

Newborn neurons generated by adult hippocampal NSPCs go through different stages of development on their way to becoming mature neurons that integrate into the dentate circuitry (Ming and Song, 2011). Previous studies have implicated diverse signaling pathways in regulating different stages of adult hippocampal neurogenesis (Zhao et al., 2008). Small Rho GTPases are downstream of many signaling pathways, but their role in the 
context of adult neurogenesis remains unclear. Studies in the past have mainly relied on in vitro models to explore the functions of small Rho GTPases and have shown that they are central signaling moieties that play diverse roles in cell division, shape, motility, and polarity (for review, see Govek et al., 2005). Collectively, these studies highlight that Cdc42 and Rac1 signaling is highly context dependent, making it important to study them in the relevant cell type both in vitro and in vivo.

We found that Cdc42 is critical for the proliferation of NSPCs in the adult hippocampus, whereas Racl appears to be dispensable for NSPC proliferation in vivo. This is in contrast with studies during development, which have shown that both Cdc42 and Racl are important for keeping embryonic cortical/telencephalic progenitors in cell cycle, specifically downstream of EGF-induced proliferation (Fuchs et al., 2009; Leone et al., 2010). Hence, a possible explanation for the observed difference between the roles of Rac1 in the proliferation of embryonic versus adult NSPCs is that EGF may not be driving proliferation in the adult neurogenic niches (Fuchs et al., 2009). In support of this, we found that EGF-driven proliferation of mouse hippocampal NSPCs in vitro (Fig. 2E, F) requires Racl activity, whereas proliferation with FGF alone does not require Racl activity. In contrast, Cdc42 appears to be involved in proliferation by both EGF and FGF (Fig. 2C,D). Given that our in vivo data resemble this phenotype (Fig. 4), it is plausible that NSPC proliferation within the adult dentate niche is not induced by EGF and hence does not require Racl activity for proliferation.

We further found that knockdown of Cdc42 activity affects dendritic growth at both 15 and $30 \mathrm{dpi}$, whereas Racl activity specifically affects dendritic growth only at $30 \mathrm{dpi}$. Previous studies have shown that DISC1, Cdk5, CREB, and tonic GABAergic input contribute to morphological maturation of immature (14 dpi) adult-born neurons (Ge et al., 2006; Duan et al., 2007; Jessberger et al., 2008; Jagasia et al., 2009). These molecules were found to influence dendritic development already at the early stages of neuronal development by 2 weeks after birth. Together with the finding that Cdc42 is important in these early steps of neuronal maturation, one might speculate that $\mathrm{Cdc} 42$ integrates several signaling pathways, finally transducing their effect on the cell cytoskeleton. GABA-mediated excitation in early stages of adult neurogenesis is known to contribute to the development and morphological maturation of adult-born hippocampal neurons (Ge et al., 2006). In this context, it is plausible to hypothesize that the upstream activator of Cdc42 Collybistin and its binding partner Gephyrin, a scaffolding protein of the inhibitory postsynapse, may translate the early effects of GABA on the morphological development of adult-born neurons via modulation of Cdc 42 (Kins et al., 2000; Poulopoulos et al., 2009).

In striking contrast to the role of Cdc42 in early steps of neuronal differentiation, we identified Racl to be a novel regulator of dendritic maturation that is restricted to later stages of neuronal development. Newborn neurons start developing spines and receiving excitatory input by $\sim 2$ weeks after birth (Zhao et al., 2008). Given the late effects of Racl knockdown on dendritic development and published findings indicating activity-mediated regulation of Rac1, Rac1 may mediate activitydependent cytoskeletal rearrangement and regulate elongation and stabilization of dendritic arbors (Impey et al., 2010). Several changes occur between 15 and $30 \mathrm{~d}$ after birth in adult-born hippocampal neurons, including formation of functional synaptic contacts, increased neurotrophin signaling, and upregulation of the brain-derived neurotrophic factor (BDNF) receptor TrkB (Donovan et al., 2008; Mattson, 2008). Miyamoto et al. (2006) have shown that BDNF-TrkB signaling promotes neurite outgrowth via Racl in primary hippocampal neurons, raising the possibility that BDNF signaling may similarly recruit Racl during later stages of development to regulate dendritic growth of adultborn neurons.

In addition to the effects on dendritic maturation, we observed that both DN-Cdc42 and DN-Rac1 overexpression led to a significant reduction in the density and percentage of mushroom spines of adult-born hippocampal neurons. It is interesting to note that, although total spine density is not altered, given the significantly shorter dendrites, we can deduce that the total number of spines per neuron would be also be reduced. Our data corroborate published in vitro findings showing that Racl and Cdc42 localize to the bulging edge of spines and promote actin polymerization and spine motility and counteract the retracting effect of Rho (Tashiro and Yuste, 2004; Murakoshi et al., 2011). The fact that mushroom spines were specifically affected underscores the importance of Cdc42 and Racl in mediating subtler aspects of spine maturation rather than spine formation itself.

In summary, using conditional deletion of Cdc 42 and Racl in adult NSPCs, we show that Cdc42 but not Rac1 is critically important for the proliferation of adult hippocampal NSPCs. Furthermore, we demonstrate that cell-autonomous knockdown of Cdc42 and Rac1 activity results in stage-specific impairments of dendritic development and spine morphogenesis. Our findings suggest that their temporally distinct roles may be attributable to differential recruitment of Cdc42 and Rac1 in the course of neuronal maturation. Together, we provide novel evidence for cellautonomous and stage-specific functions of the small Rho GTPases Cdc42 and Racl in adult hippocampal neurogenesis.

\section{References}

Artegiani B, Lindemann D, Calegari F (2011) Overexpression of cdk4 and cyclinD1 triggers greater expansion of neural stem cells in the adult mouse brain. J Exp Med 208:937-948. CrossRef Medline

Cappello S, Attardo A, Wu X, Iwasato T, Itohara S, Wilsch-Bräuninger M, Eilken HM, Rieger MA, Schroeder TT, Huttner WB, Brakebusch C, Götz M (2006) The Rho-GTPase cdc42 regulates neural progenitor fate at the apical surface. Nat Neurosci 9:1099-1107. CrossRef Medline

Chrostek A, Wu X, Quondamatteo F, Hu R, Sanecka A, Niemann C, Langbein L, Haase I, Brakebusch C (2006) Racl is crucial for hair follicle integrity but is not essential for maintenance of the epidermis. Mol Cell Biol 26: 6957-6970. CrossRef Medline

Cooper-Kuhn CM, Vroemen M, Brown J, Ye H, Thompson MA, Winkler J, Kuhn HG (2002) Impaired adult neurogenesis in mice lacking the transcription factor E2F1. Mol Cell Neurosci 21:312-323. CrossRef Medline

Donovan MH, Yamaguchi M, Eisch AJ (2008) Dynamic expression of TrkB receptor protein on proliferating and maturing cells in the adult mouse dentate gyrus. Hippocampus 18:435-439. CrossRef Medline

Duan X, Chang JH, Ge S, Faulkner RL, Kim JY, Kitabatake Y, Liu XB, Yang CH, Jordan JD, Ma DK, Liu CY, Ganesan S, Cheng HJ, Ming GL, Lu B, Song H (2007) Disrupted-In-Schizophrenia 1 regulates integration of newly generated neurons in the adult brain. Cell 130:1146-1158. CrossRef Medline

Dumitriu D, Rodriguez A, Morrison JH (2011) High-throughput, detailed, cell-specific neuroanatomy of dendritic spines using microinjection and confocal microscopy. Nat Protoc 6:1391-1411. CrossRef Medline

Espósito MS, Piatti VC, Laplagne DA, Morgenstern NA, Ferrari CC, Pitossi FJ, Schinder AF (2005) Neuronal differentiation in the adult hippocampus recapitulates embryonic development. J Neurosci 25:10074-10086. CrossRef Medline

Fuchs S, Herzog D, Sumara G, Büchmann-Møller S, Civenni G, Wu X, Chrostek-Grashoff A, Suter U, Ricci R, Relvas JB, Brakebusch C, Sommer L (2009) Stage-specific control of neural crest stem cell proliferation by the small rho GTPases Cdc42 and Racl. Cell Stem Cell 4:236-247. CrossRef Medline

Fukata M, Nakagawa M, Kaibuchi K (2003) Roles of Rho-family GTPases in 
cell polarisation and directional migration. Curr Opin Cell Biol 15:590597. CrossRef Medline

Ge S, Goh EL, Sailor KA, Kitabatake Y, Ming GL, Song H (2006) GABA regulates synaptic integration of newly generated neurons in the adult brain. Nature 439:589-593. CrossRef Medline

Govek EE, Newey SE, Van Aelst L (2005) The role of the Rho GTPases in neuronal development. Genes Dev 19:1-49. CrossRef Medline

Govek EE, Hatten ME, Van Aelst L (2011) The role of Rho GTPase proteins in CNS neuronal migration. Dev Neurobiol 71:528-553. CrossRef Medline

Hodge RD, Hevner RF (2011) Expression and actions of transcription factors in adult hippocampal neurogenesis. Dev Neurobiol 71:680-689. CrossRef Medline

Impey S, Davare M, Lesiak A, Fortin D, Ando H, Varlamova O, Obrietan K, Soderling TR, Goodman RH, Wayman GA (2010) An activity-induced microRNA controls dendritic spine formation by regulating Rac1-PAK signaling. Mol Cell Neurosci 43:146-156. CrossRef Medline

Jaffe AB, Hall A (2005) Rho GTPases: biochemistry and biology. Annu Rev Cell Dev Biol 21:247-269. CrossRef Medline

Jagasia R, Steib K, Englberger E, Herold S, Faus-Kessler T, Saxe M, Gage FH, Song H, Lie DC (2009) GABA-cAMP response element-binding protein signaling regulates maturation and survival of newly generated neurons in the adult hippocampus. J Neurosci 29:7966-7977. CrossRef Medline

Jawerka M, Colak D, Dimou L, Spiller C, Lagger S, Montgomery RL, Olson EN, Wurst W, Göttlicher M, Götz M (2010) The specific role of histone deacetylase 2 in adult neurogenesis. Neuron Glia Biol 6:93-107. CrossRef Medline

Jessberger S, Aigner S, Clemenson GD Jr, Toni N, Lie DC, Karalay O, Overall R, Kempermann G, Gage FH (2008) Cdk5 regulates accurate maturation of newborn granule cells in the adult hippocampus. PLoS Biol 6:e272. CrossRef Medline

Jessberger S, Gage FH, Eisch AJ, Lagace DC (2009) Making a neuron: Cdk5 in embryonic and adult neurogenesis. Trends Neurosci 32:575-582. CrossRef Medline

Karalay O, Doberauer K, Vadodaria KC, Knobloch M, Berti L, Miquelajauregui A, Schwark M, Jagasia R, Taketo MM, Tarabykin V, Lie DC, Jessberger S (2011) Prospero-related homeobox 1 gene (Prox1) is regulated by canonical Wnt signaling and has a stage-specific role in adult hippocampal neurogenesis. Proc Natl Acad Sci US A 108:5807-5812. CrossRef Medline

Kempermann G, Jessberger S, Steiner B, Kronenberg G (2004) Milestones of neuronal development in the adult hippocampus. Trends Neurosci 27:447-452. CrossRef Medline

Kins S, Betz H, Kirsch J (2000) Collybistin, a newly identified brain-specific GEF, induces submembrane clustering of gephyrin. Nat Neurosci 3:2229. CrossRef Medline

Koivisto L, Häkkinen L, Matsumoto K, McCulloch CA, Yamada KM, Larjava H (2004) Glycogen synthase kinase-3 regulates cytoskeleton and translocation of Rac1 in long cellular extensions of human keratinocytes. Exp Cell Res 293:68-80. CrossRef Medline

Lagace DC, Whitman MC, Noonan MA, Ables JL, DeCarolis NA, Arguello AA, Donovan MH, Fischer SJ, Farnbauch LA, Beech RD, DiLeone RJ, Greer CA, Mandyam CD, Eisch AJ (2007) Dynamic contribution of nestin-expressing stem cells to adult neurogenesis. J Neurosci 27:12623-12629. CrossRef Medline

Leone DP, Srinivasan K, Brakebusch C, McConnell SK (2010) The rho GTPase Racl is required for proliferation and survival of progenitors in the developing forebrain. Dev Neurobiol 70:659-678. CrossRef Medline
Mattson MP (2008) Glutamate and neurotrophic factors in neuronal plasticity and disease. Ann N Y Acad Sci 1144:97-112. CrossRef Medline

Meijering E, Jacob M, Sarria JC, Steiner P, Hirling H, Unser M (2004) Design and validation of a tool for neurite tracing and analysis in fluorescence microscopy images. Cytometry A 58:167-176. CrossRef Medline

Ming GL, Song H (2011) Adult neurogenesis in the mammalian brain: significant answers and significant questions. Neuron 70:687-702. CrossRef Medline

Miyamoto Y, Yamauchi J, Tanoue A, Wu C, Mobley WC (2006) TrkB binds and tyrosine-phosphorylates Tiam1, leading to activation of Rac1 and induction of changes in cellular morphology. Proc Natl Acad Sci U S A 103:10444-10449. CrossRef Medline

Murakoshi H, Wang H, Yasuda R (2011) Local, persistent activation of Rho GTPases during plasticity of single dendritic spines. Nature 472:100-104. CrossRef Medline

Poulopoulos A, Aramuni G, Meyer G, Soykan T, Hoon M, Papadopoulos T, Zhang M, Paarmann I, Fuchs C, Harvey K, Jedlicka P, Schwarzacher SW, Betz H, Harvey RJ, Brose N, Zhang W, Varoqueaux F (2009) Neuroligin 2 drives postsynaptic assembly at perisomatic inhibitory synapses through gephyrin and collybistin. Neuron 63:628-642. CrossRef Medline

Preibisch S, Saalfeld S, Tomancak P (2009) Globally optimal stitching of tiled 3D microscopic image acquisitions. Bioinformatics 25:1463-1465. CrossRef Medline

Ray J, Gage FH (2006) Differential properties of adult rat and mouse brainderived neural stem/progenitor cells. Mol Cell Neurosci 31:560-573. CrossRef Medline

Schmetsdorf S, Gärtner U, Arendt T (2005) Expression of cell cycle-related proteins in developing and adult mouse hippocampus. Int J Dev Neurosci 23:101-112. CrossRef Medline

Schmitz AA, Govek EE, Böttner B, Van Aelst L (2000) Rho GTPases: signaling, migration, and invasion. Exp Cell Res 261:1-12. CrossRef Medline

Tashiro A, Yuste R (2004) Regulation of dendritic spine motility and stability by Racl and Rho kinase: evidence for two forms of spine motility. Mol Cell Neurosci 26:429-440. CrossRef Medline

Tashiro A, Zhao C, Gage FH (2006) Retrovirus-mediated single-cell gene knockout technique in adult newborn neurons in vivo. Nat Protoc 1:3049-3055. CrossRef Medline

Toni N, Teng EM, Bushong EA, Aimone JB, Zhao C, Consiglio A, van Praag H, Martone ME, Ellisman MH, Gage FH (2007) Synapse formation on neurons born in the adult hippocampus. Nat Neurosci 10:727-734. CrossRef Medline

Toni N, Laplagne DA, Zhao C, Lombardi G, Ribak CE, Gage FH, Schinder AF (2008) Neurons born in the adult dentate gyrus form functional synapses with target cells. Nat Neurosci 11:901-907. CrossRef Medline

Wu X, Quondamatteo F, Lefever T, Czuchra A, Meyer H, Chrostek A, Paus R, Langbein L, Brakebusch C (2006) Cdc42 controls progenitor cell differentiation and beta-catenin turnover in skin. Genes Dev 20:571-585. CrossRef Medline

Yamaguchi M, Saito H, Suzuki M, Mori K (2000) Visualization of neurogenesis in the central nervous system using nestin promoter-GFP transgenic mice. Neuroreport 11:1991-1996. CrossRef Medline

Zhao C, Teng EM, Summers RG Jr, Ming GL, Gage FH (2006) Distinct morphological stages of dentate granule neuron maturation in the adult mouse hippocampus. J Neurosci 26:3-11. CrossRef Medline

Zhao C, Deng W, Gage FH (2008) Mechanisms and functional implications of adult neurogenesis. Cell 132:645-660. CrossRef Medline 